\title{
Effects of cadmium toxicity on sesame seed germination explained by various nonlinear growth models
}

\author{
Ghasem Parmoon ${ }^{1}$, Seyed Amir Moosavi ${ }^{2, *}$, Adel Poshtdar ${ }^{2}$ and Seyed Ataollah Siadat ${ }^{2}$ \\ 1 Agronomy, Department of Agronomy and Plant Breeding, Faculty of Agriculture, University of Mohaghegh Ardabili, Ardabil, Iran \\ 2 Department of Plant Production and Genetics, Faculty of Agriculture, Agricultural Sciences and Natural Resources University of \\ Khuzestan, Mollasani, Khuzestan, Iran
}

Received 1 September 2019 - Accepted 1 October 2020

\begin{abstract}
This experiment was conducted to evaluate the effects of cadmium toxicity on the seed germination properties of sesame cultivars (Halil, Nazok Shakhei, Oltan, and Yellow White) using nonlinear growth models. Seeds were germinated in petri dishes $(90 \mathrm{~mm}$ diameter), with a double layered of filter paper soaked in distilled water as control treatment or cadmium (CdSO4) solutions in concentrations of $0,100,200,400,600,800$ and $1000 \mathrm{ppm}$. Each treatment was replicated four times and included 50 seeds in each petri dishes. Hyperbolastic growth models for the description of seed germination data were compared to Richards, Weibull, Logistic and Gompertz models. Our results revealed that all studied cultivars were germinated at the cadmium-polluted germination medium to a maximum of $200 \mathrm{ppm}$ without reduction in germination fraction, while seed germination rate was decreased at this concentration compared to 0 and $100 \mathrm{ppm}$. Increasing cadmium concentration resulted in the germination fraction reduction from 1 to 0.4 at the $400 \mathrm{ppm}$. The recommended hyperbolastic growth model was type III or (H3) as it provided the best model with the lowest Corrected Akaike Information Criterion for cv. Halil $(\mathrm{AICc}=-14.6)$ and $\mathrm{cv}$. Nazok Shakhei, $(\mathrm{AICc}=-14.2)$.
\end{abstract}

Keywords: Germination / growth model / heavy metal / pollution / sesame

Résumé - Les effets de la toxicité du cadmium sur la germination de graines de sésame expliqués par divers modèles de croissance non linéaire. Cette expérience a été menée pour évaluer les effets de la toxicité du cadmium sur la cinétique de germination de graines issues de différents cultivars de sésame (Halil, Nazok Shakhei, Oltan et Yellow White), en comparant des modèles de croissance non linéaire. Les graines ont germé dans des boîtes de Pétri $(90 \mathrm{~mm}$ de diamètre), entre deux couches de papier filtre imbibées d'eau distillée (contrôle) ou dans des solutions de cadmium (CdSO4) à des concentrations de $0,100,200,400,600,800$ et $1000 \mathrm{ppm}$. Chaque traitement a été répété quatre fois et comprenait 50 graines par boîte. Les cinétiques de croissances ont été modélisées avec modèles de croissance hyperbolastique, dont l'ajustement a été comparé aux modèles sigmoïdes classiques (Richards, Weibull, Logistic et Gompertz). Nos résultats ont révélé que tous les cultivars étudiés ont germé, sans réduction du taux de germination, jusqu'à une concentration de de $100 \mathrm{ppm}$. Au-delà, le taux de germination était réduit. À la concentration de $400 \mathrm{ppm}$, le taux de germination est passé de 1 à 0,4 . Le modèle de croissance hyperbolastique recommandé était de type III ou (H3), car il présentait un critère d'information d'Akaike (AIC) corrigé le plus bas pour les cultivars Halil $(\mathrm{AICc}=-14,6)$ et Nazok Shakhei, $(\mathrm{AICc}=-14,2)$.

Mots clés : Germination / modèle de croissance / métal lourd / pollution / sésame

\footnotetext{
* Correspondence: amirmoosavi@asnrukh.ac.ir;

amir.msa@gmail.com
} 


\section{Introduction}

Industrialization and human activities caused serious environmental pollution by heavy metals. This not only causes direct hazardous effects to both human and ecosystems, but has also influenced food safety and security in agriculture lands (Das et al., 1997; Benavides et al., 2005). Cadmium is a heavy metal that does not have any known nutritious function for plants (Hanc et al., 2009; Gallego et al., 2012). However, due to the increase of mine production, industrial activities and urbanization, its concentrations in the environment has increased drastically. Cadmium is considered a highly significant pollutant due to its high toxicity and large water solubility (Benavides et al., 2005). It has been accepted that cadmium can interfere with water uptake and reduce root growth and development of plants (DalCorso et al., 2008). Exploring the interaction of cadmium and seed germination is important for the safety of crop production. It is also worth to study the risks of good and uniform seed germination in the soils with various levels of cadmium contaminations.

Modeling biological data conveniently summarizes information into small sets of parameters that can be interpreted biologically. Growth models are mainly empirical and they rely on physiological or biochemical mechanisms (Eby et al., 2017). Generally, growth models are expressed as the rate function of an independent variable over time. It is very important to consider that each growth function must be biologically meaningful. The benefits of nonlinear regression analysis in seed biology is due to their interpretability, parsimony and prediction possibility for biologically related phenomena, especially outside the range of actual experimental data (Archontoulis and Miguez, 2015). Many nonlinear growth models have been successfully applied in biological science. Gompertz, Richards, Weibull, Logistic and Hill are the most applied nonlinear functions to describe cumulative seed germination (Dumur et al., 1990; Shafii et al., 1991; Tjørve and Tjørve, 2017). The number of parameters in each model varies from three to five depending on the mathematical bases of the model construction method, to provide the best curve fit for experimental data. In the logistic model, the period to reach the maximum growth rate is equal to the inflection point, thus, this model is symmetric around the maximum growth rate. In contrast, Richards and Gompertz models have different durations for short and fast growth rates and they are considered asymmetric models (Shafii et al., 1991). Recent reports suggested that hyperbolastic nonlinear growth models in some cases provide a better fit for complex growth patterns in biological studies, over more traditional models such as generalized Gompertz or logistic functions (Tabatabai et al., 2005; Ahmadi and Golian, 2008; Eby et al., 2017; Barrera et al., 2018). Hyperbolastic models were introduced by Tabatabai et al. to study tumor and stem cells growth rates (Tabatabai et al., 2005). The term Hyperbolastic for this type of nonlinear models comes from the model function equation showing that these models are a function of the inverse hyperbolic sine (Ahmadi and Golian, 2008). Hyperbolastic growth models are classified into three types: H1, H2 and H3, according to their function. Hyperbolastic growth models are developed to provide higher accuracy and more flexibility, compared to other growth models such as Gompertz, Weibull, and others (Eby et al., 2017).

The purpose of our study was to evaluate the possible application of Hyperbolastic models to fit empirical data obtained from an experiment exploring the influence of various concentrations of heavy metals on sesame genotypes.

\section{Material and methods}

Seeds of sesame (Sesame indicum L.) cultivars were obtained from the oil seed division at the Seed and Plant Improvement Institute in Karaj, Iran in 2018. Seeds of five sesame cultivars (Halil, Nazok Shakhei, Oltan, and Yellow White) were used in this experiment, and generally followed the ISTA rules for standard seed germination test (ISTA, 2017). The seeds were germinated in petri dishes $(90 \mathrm{~mm}$ diameter), with a double layered of filter paper soaked in distilled water as control treatment or cadmium $\left(\mathrm{CdSO}_{4}\right)$ solutions in concentrations of $0,100,200,400,600,800$ and $1000 \mathrm{ppm}$. Each treatment was replicated four times and included 50 seeds in each petri dishes. Seeds were subjected to standard seed germination tests using top of paper method and at alternate temperature regime $\left(20 / 30^{\circ} \mathrm{C}\right)$ under dark conditions (ISTA, 2013). The number of germinated seeds were recorded every $12 \mathrm{~h}$ until day six after test initiation. Germination test was ended when seed germination was reached to the maximum and no seeds have germinated for three subsequent counts.

\subsection{Statistical analyses}

Two-way ANOVA with Tukey's post-hoc analysis (Seal et al., 2018) was used to analyze the effects of cultivar, concentrations of cadmium, and their interaction on seed germination and the germination index of sesame. Analysis of variance and comparison of means were conducted using the Minitab 18 statistical software. The Software SigmaPlot (SigmaPlot 14, Systat Software, Inc.) was used for non-linear regression analyses and model fit on seed germination data.

Seed germination index was calculated according to (Fenner and Edwards, 1991). In this study various nonlinear growth models were applied on the cumulative seed germination data, in order to make an appropriate comparison between hyberbolastic models and other models generally applied in seed biology. The applied hyperbolastic models have been previously explained using three different models of $\mathrm{H} 1$ to $\mathrm{H} 3$, and are presented in equations (1) to (3) below (Tabatabai et al., 2005; Ahmadi and Golian, 2008; Eby et al., 2017). The hyperbolastic growth rate of type I (H1) (Tabatabai et al., 2005) is:

$$
P(t)=\frac{Y \max }{1+\alpha \exp [-Y \max \beta t-\theta \arcsin h(t)]},
$$

Where:

$$
\alpha=\frac{Y \max -P 0}{P 0} \exp [Y \max \beta t 0+\theta \operatorname{arcsinh}(t 0)],
$$


Where $\mathrm{P}(\mathrm{t})$ is the number of germinated seeds at time $\mathrm{t}$, the constant Ymax is the parameter representing carrying capacity, and $\beta$ and $\theta$ are constants. It is worth noting that both $\beta$ and $\theta$ are parameters that describe growth (germination) rate. The $\operatorname{arcsinh}(t)$ is the inverse hyperbolic sine function of $t$.

The hyperbolastic growth rate of type II (H2) (Tabatabai et al., 2005) is:

$$
\begin{aligned}
P(t) & =\frac{Y \max }{1+\alpha \operatorname{arcsinh}\left[\exp \left(-Y \max \beta t^{\gamma}\right)\right]}, \\
\alpha & =\frac{Y \max -P_{0}}{P_{0} \operatorname{arcsinh}\left[\exp \left(-Y \max \beta t_{0}{ }^{\gamma}\right)\right]} .
\end{aligned}
$$

With the initial condition $\mathrm{P}\left(\mathrm{t}_{0}\right)=\mathrm{P}_{0}$; and Ymax, $\beta$, and $\gamma$ as parameters. The growth rate is determined using $\beta$ (intrinsic growth rate) and $\gamma$ (allometric constant).

The hyperbolastic growth rate of type III (H3) (Tabatabai et al., 2005) is:

$$
\begin{gathered}
P(t)=Y \max -\alpha \exp \left[-\beta t^{\gamma}-\operatorname{arcsinh}(\theta t),\right. \\
\alpha=\left(Y \max -P_{0}\right) \exp \left[\beta t_{0}^{\gamma}+\operatorname{arcsinh}\left(\theta t_{0}\right)\right] .
\end{gathered}
$$

With the initial condition $\mathrm{P}\left(\mathrm{t}_{0}\right)=\mathrm{P}_{0}$; and $\mathrm{Ymax}, \beta$ (by the time prescribed for the, final count), $\gamma$ (allometric constant) and the distance from symmetric sigmoidal growth is determined by the value of $|\theta|$.

In hyperbolastic models $\mathrm{H} 1, \mathrm{H} 2$ and $\mathrm{H} 3$ the parameter Ymax will represent the maximum fraction of germination percentage, while the parameter $\beta$ will represent the rate of increase of seed germination with respect to time. In $\mathrm{H} 1$ the additional parameter $\theta$ helps determine variation in the intrinsic rate. In $\mathrm{H} 2$ the additional parameter $\gamma$ is an allometric parameter that also provides departure from logistic symmetry by rescaling, and the effective rate is determined by both $\beta$ and $\gamma$. Finally, the parameter $\gamma$ in $\mathrm{H} 3$ is an allometric parameter as in $\mathrm{H} 2$, while $\theta$ is a shape parameter, and its role is comparable to the role in $\mathrm{H} 1$ and $\mathrm{H} 2$; and $\beta, \gamma$, and $\theta$ collectively determine the effective growth rate.

A three parameter logistic function is fitted on our experimental data using equation (4) (Verhulst, 1838; Tanveer et al., 2017; Soler-Guilhen et al., 2020). An additional parameter, $\mathrm{d}$, has the effect of shifting the graph vertically (the lower asymptote), and it turns the three-parameter logistic to a four-parameter logistic function (Eq. (5)).

$$
\begin{gathered}
\mathrm{Y}=\mathrm{Ymax}[1+\exp (\mathrm{L}-\mathrm{Kt})]-1, \\
\mathrm{Y}=\mathrm{d}+\mathrm{Ymax}[1+\exp (\mathrm{L}-\mathrm{Kt})]-1 .
\end{gathered}
$$

$\mathrm{Y}$ is the cumulative percentage of germination at time $t, \mathrm{Ymax}$ is the maximum rate of seed germination (the upper asymptote), $\mathrm{K}$ is the increasing rate of germination, $\mathrm{L}$ is time scale constant, and $\mathrm{d}$ is the lower asymptote.

Gompertz is a sigmoid model which has been widely used to curve fitting of growth data. The three- and four-parameter Gompertz functions were fitted on data using the following equations (Gompertz, 1825; Tjørve and Tjørve, 2017):

$$
\begin{gathered}
\mathrm{Y}=\mathrm{Ymax}[\exp (-\exp (\mathrm{L}-\mathrm{Kt}))], \\
\mathrm{Y}=\mathrm{d}+\mathrm{Ymax}[\exp (-\exp (\mathrm{L}-\mathrm{Kt}))] .
\end{gathered}
$$

Richards' function is a modified to a four-parameter sigmoid function having an especial shape parameter to provide a flexible curve fitting our experimental data. This model was fitted to our experimental data using equation (8) (Richards, 1959).

$$
\mathrm{Y}=\mathrm{Ymax}[1-\exp (-\mathrm{K}(\mathrm{t}-\mathrm{L}))] 1 /(1-\mathrm{c}) .
$$

$\mathrm{Y}$ is the cumulative percentage of germination at time $t, \mathrm{Ymax}$ is the maximum rate of seed germination (the upper asymptote), $\mathrm{K}$ is the increasing rate of germination, $\mathrm{L}$ is time scale constant, and $\mathrm{c}$ is the shape parameter to provide a flexible curve fitting our experimental data.

Weibull function has also been successfully applied in seed germination studies by many researchers. This model not only have biologically interpretable parameters, but also have unique properties when the exponential distribution is not well explained for experimental data due to the limitations of randomization (Shafii et al., 1991). A Weibull model was fitted to our experimental data using the following equation (Weibull, 1951):

$$
\mathrm{Y}=\mathrm{Ymax}[1-\exp (-\mathrm{K}(\mathrm{t}-\mathrm{L})) c)] .
$$

These models were applied to a cumulative fraction dataset of sesame cultivars seed germination, using nonlinear regression to estimate the parameters for each model. The statistical calculations for the determination coefficient $\left(\mathrm{R}^{2}\right)$ was used to assess the accuracy of each model. However, it should be noted that $\mathrm{R}^{2}$ may not always represent the most appropriate metric because it does not account for the number of parameters in the model (Archontoulis and Miguez, 2015). To increase the precision of the model selection criterion, the Corrected Akaike Information Criterion (AICc) was calculated for all applied models. Data with a probability index resulted in a lower AICc and better fit to the data (Bullied et al., 2012).

$$
R^{2}=1-\frac{(\text { residual sum of squares })}{\text { Total sum of squares }},
$$

$$
\begin{aligned}
\mathrm{AIC}= & n \ln \left(\frac{\text { residual sum of squares }}{n}\right)+2 k, \\
\mathrm{AICc}= & \operatorname{nln}\left(\frac{\text { residual sum of squares }}{n}\right)+2 k \\
& +\left(\frac{2 k(k+1)}{n-k-1}\right),
\end{aligned}
$$

Where $\mathrm{n}$ is the number of observations, and $k$ is the number of model parameters (Burnham and Anderson, 2002). 
Table 1. The analysis of variance and comparison of means for seed germination traits of sesame cultivars exposed to various levels of cadmium concentrations.

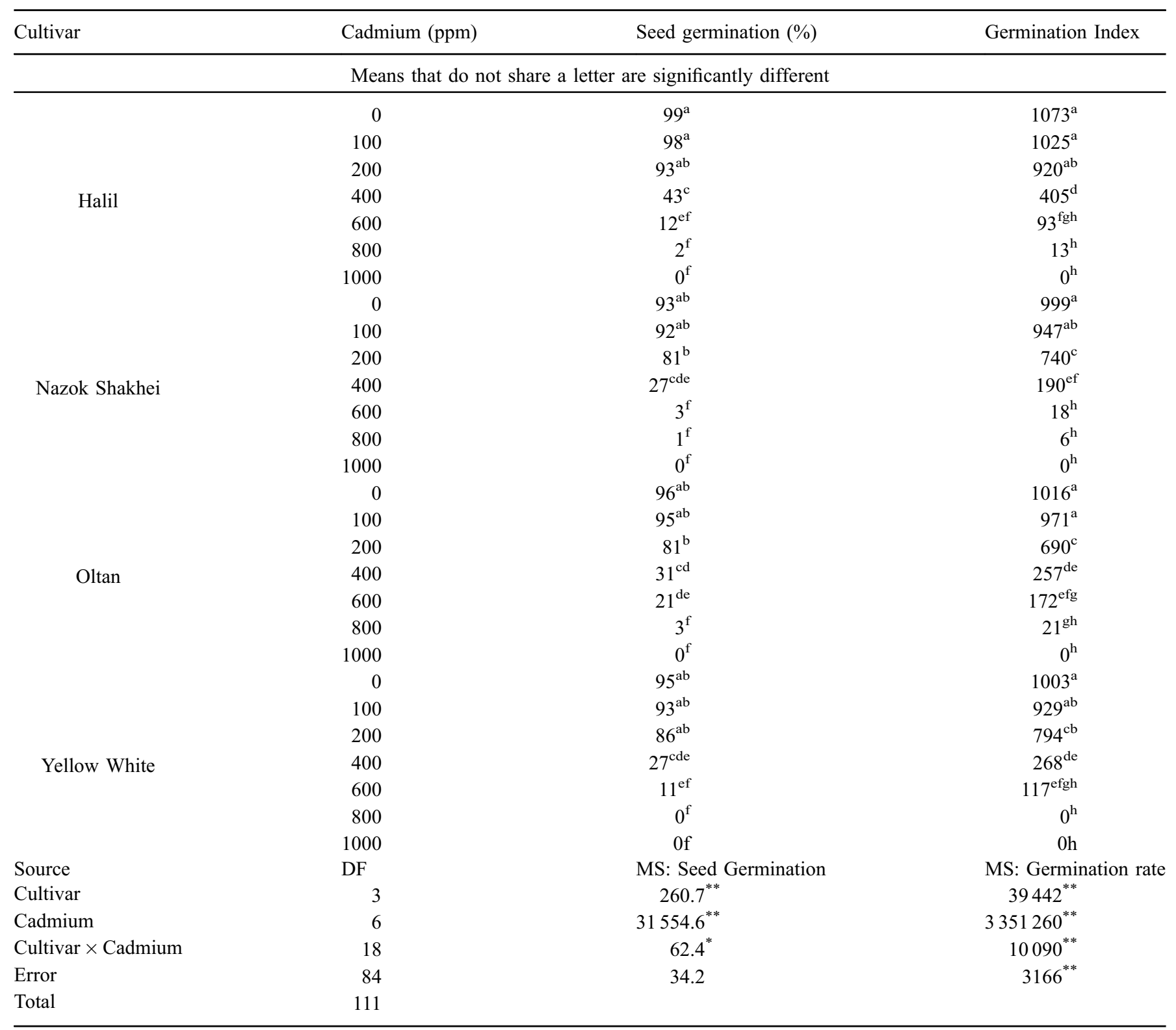

${ }^{*}$ Significant $(P \leq 0.05) ;{ }^{* *}$ Significant $(P \leq 0.01)$.

\section{Results and discussion}

Seed germination of all sesame cultivars declined as the cadmium concentration increased. Our results revealed that sesame seeds are tolerated to $200 \mathrm{ppm}$ of cadmium. However, the germination rate declined as the cadmium contamination increased. At cadmium concentrations over $400 \mathrm{ppm}$, there was a drastic reduction of final seed germination for all the sesame cultivars (Tab. 1). Among all studied cultivars, cv. Halil exhibited the highest tolerance to cadmium toxicity up to $400 \mathrm{ppm}$, at which seed germination was $43 \%, 27 \%, 31 \%$ and $27 \%$ for cv. Halil, cv. Nazok Shakhei, Oltan and Yellow wWhite respectively (Tab. 1). The fastest seed germination was observed when there was no cadmium pollution for cv. Halil.
However, at a cadmium concentration of $600 \mathrm{ppm}$, the fastest seed germination was observed in cv. Oltan (Tab. 1). The germination index for the control treatment was 1003 for cv. Yellow White. However, the index was reduced to 117 by increasing the cadmium concentration up to $600 \mathrm{ppm}$. Similar findings regarding the reduction of seed germination due to heavy metals toxicity have been previously reported with (Akpofure, 2012; Asgher et al., 2015; Fattahi et al., 2019). It has been shown that cadmium pollution may increase seeds' indigenous abscisic acid levels and inhibit seed germination (Munzuroğlu et al., 2008). Cadmium toxicity can damage normal seed respiration during imbibition (Deswal and Laura, 2018). It has also been shown that antioxidants and amylase enzyme functionality is reduced when cadmium concentrations 


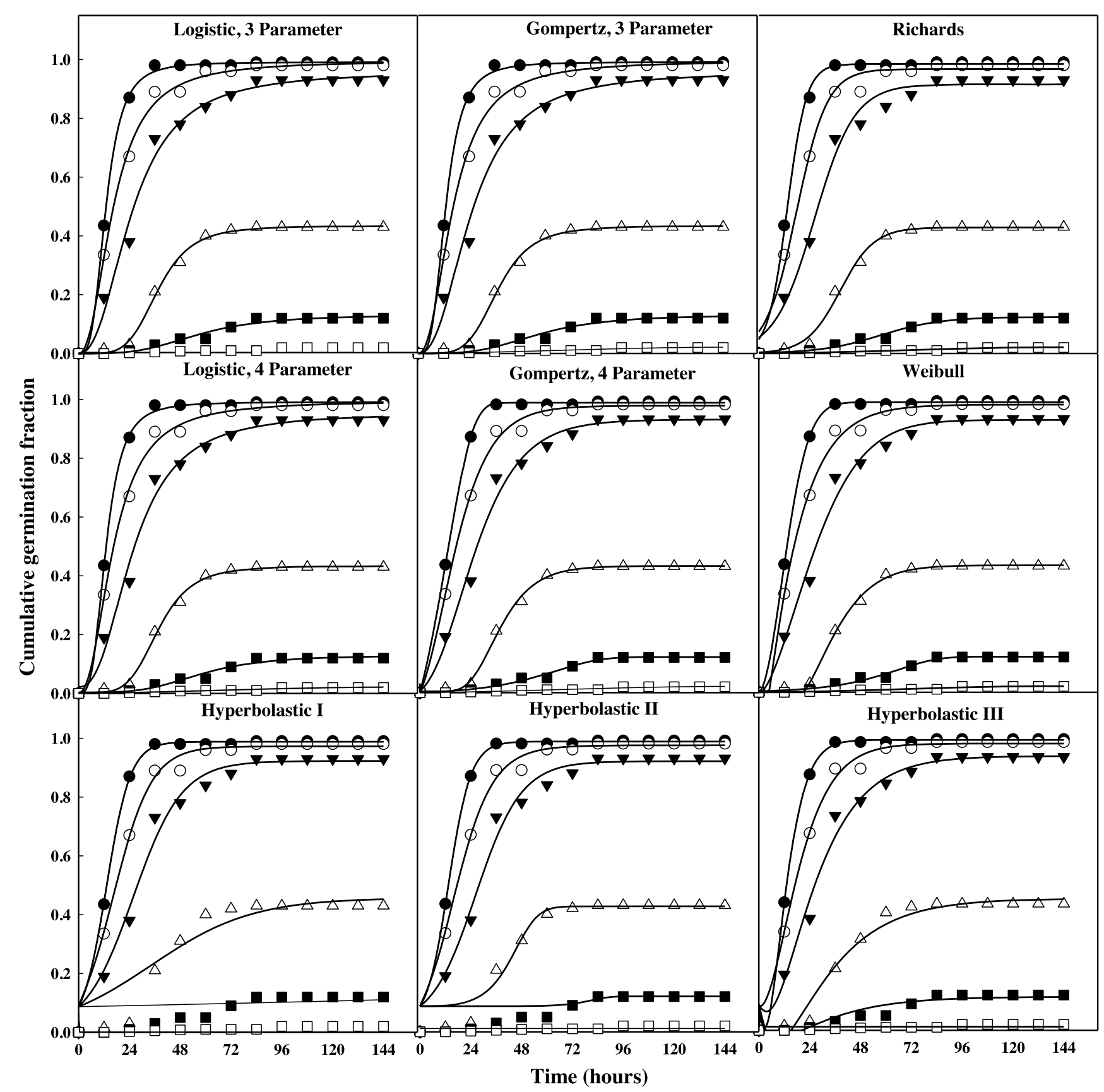

Fig. 1. Non-linear regression models for describe cumulative germination function cv. Halil under cadmium stress. Symbols $\mathbf{0}$ : 0 ppm; O: $100 \mathrm{ppm} ; \boldsymbol{\nabla}: 200 \mathrm{ppm} ; \Delta: 400 \mathrm{ppm} ; \mathbf{\square}: 600 \mathrm{ppm}$ and $\square: 800 \mathrm{ppm}$.

increase in the seed environment, causing a decrease in the seed germination rate index (Afzal et al., 2019; Chugh and Sawhney, 1996; Zhang et al., 2009).

In our case, cumulative germination fraction of cv. Halil was reduced from 1 to 0.4 at a 400 ppm cadmium concentration and to lower than 0.2 at $600 \mathrm{ppm}$. The seed germination pattern of $\mathrm{cv}$. Halil was well fitted by the sigmoid models while hyperbolastic functions were capable of describing the data with reasonable fit at cadmium concentrations of 200 ppm (Fig. 1). For instance, the estimated AICc of three-parameter logistic for cv. Halil at cadmium concentrations of $100,200,400 \mathrm{ppm}$ were -23.1 , -16.1 , and -29.0 respectively, which were the lowerst estimated AICc among other studied models. Hyperbolastic models I, II and III poorly fit the germination data above $200 \mathrm{ppm}$ cadmium concentration. In cv. Oltan for instance, the estimated AICc were 12.8, - 13.8 and - 16.4 for hyperbolastic models I, II and III; while the AICc of Gompertz $3 \mathrm{p}$ was estimated at -21.1, showing better fit compared to the hyperbolastic models.

In cv. Yellow White, the estimated AICc at cadmium concetrations of $200 \mathrm{ppm}$ was $-18.8,-15.1,-16.0,-15.6$, $-8.2,-15.8,-13.7,-14.1$ and -10.9 for three-parameter logistic, four-parameter logistic, three-paramter Gompertz, four-parameter Gompertz, Richards, Weibull and hyperbolastic Ithrough III respectively (Tab. 2). 
G. Parmoon et al:: OCL 2020, 27, 57

Table 2. Nonliner regressions to describe Cumulative seed germination fraction of sesame (Sesamum indicum L.) cultivars under cadmium contaminations. AICc is represented of the best model fit.

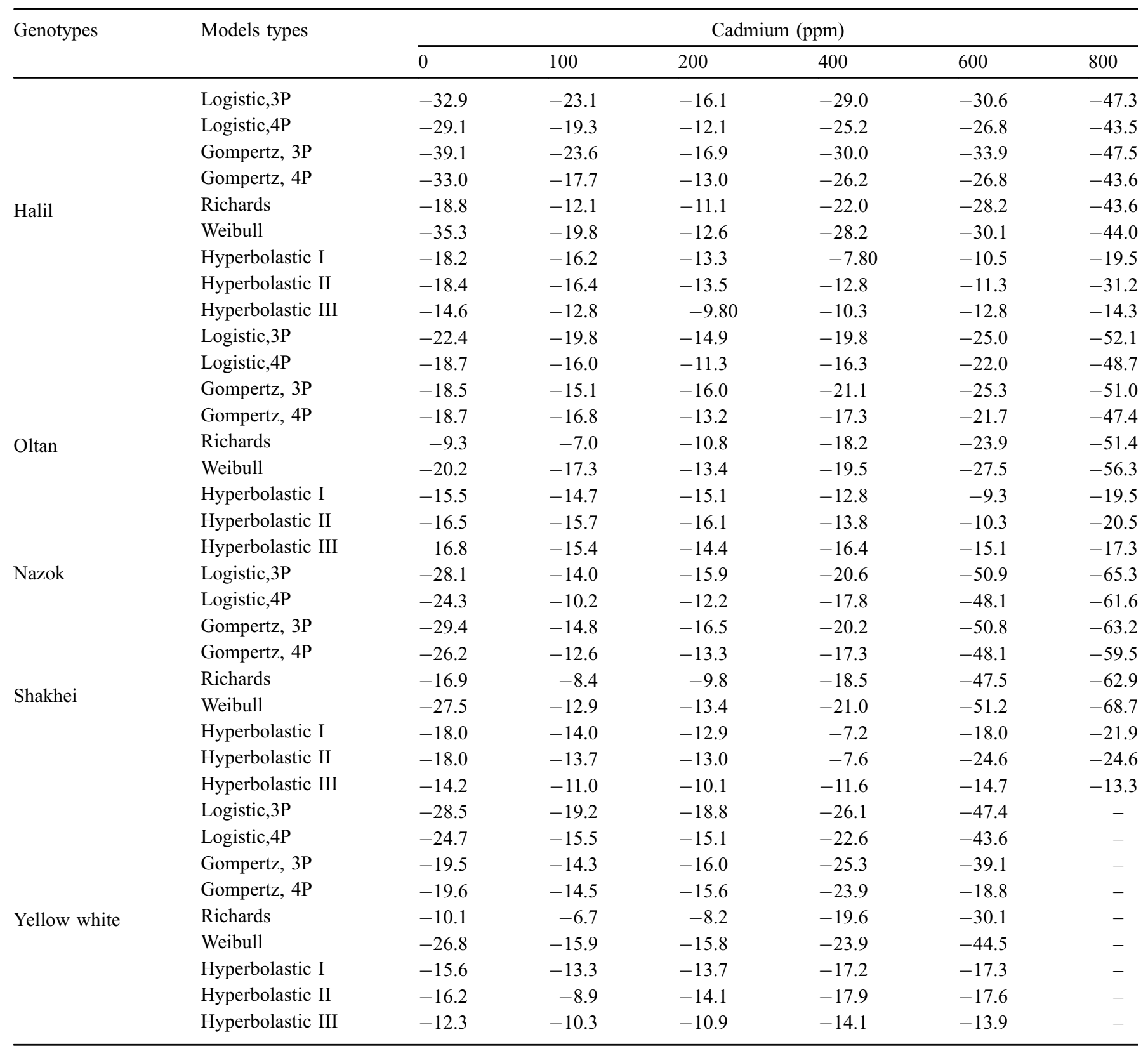

The cv. Nazok Shakhei was sensitive to cadmium toxicity and it did not germinate at the $800 \mathrm{ppm}$ concentration. The seed germination fraction reduced from 1 to 0.2 at the $400 \mathrm{ppm}$ concentration. Hyperbolastic type III was the only hyperbolic function that provided a good fit for the cadmium concentrations of 0 to $400 \mathrm{ppm}$ (Fig. 2). The seed germination rate was considerably reduced at the $200 \mathrm{ppm}$ cadmium concentration, while seeds could still germinate at the $800 \mathrm{ppm}$ cadmium concentration. Our results show that without cadmium contaminations, the best fit for the haperbolastic models were obtained from hyperbolastic II for cv. Halil $(\mathrm{AICc}=-18.4)$, hyperbolastic III for cv. Oltan $(\mathrm{AICc}=-16.5)$, hyperbolastic I for cv. Nazok Shakhei $(\mathrm{AICc}=-16.5)$ and hyperbolastic II for cv. Yellow White $(\mathrm{AICc}=-16.2)$. Increase in the cadmium concentration from 200 to $400 \mathrm{ppm}$ caused drastical reduction of the seed germination potential in all investigated cultivars. In cv. Hali and cv. Yellow White, the best model fit for all cadmium concentrations above $100 \mathrm{ppm}$ were obtained from the threeparameter logistic function.

Hyperbolastic curves fitted for the seed germination data of cv. Oltan did not satisfactoraly cover data points at high cadmium concentrations (600 to $800 \mathrm{ppm}$ ) (Fig. 3). For instance, AICc values of Hyperbolastic I and II were - 9.3 and -10.3 at the 600 ppm cadmium concentations, while the AICc values for Weibull and Logistic $3 p$ at the same cadmium concentration were -27.5 and -25 respectively (Tab. 2). 


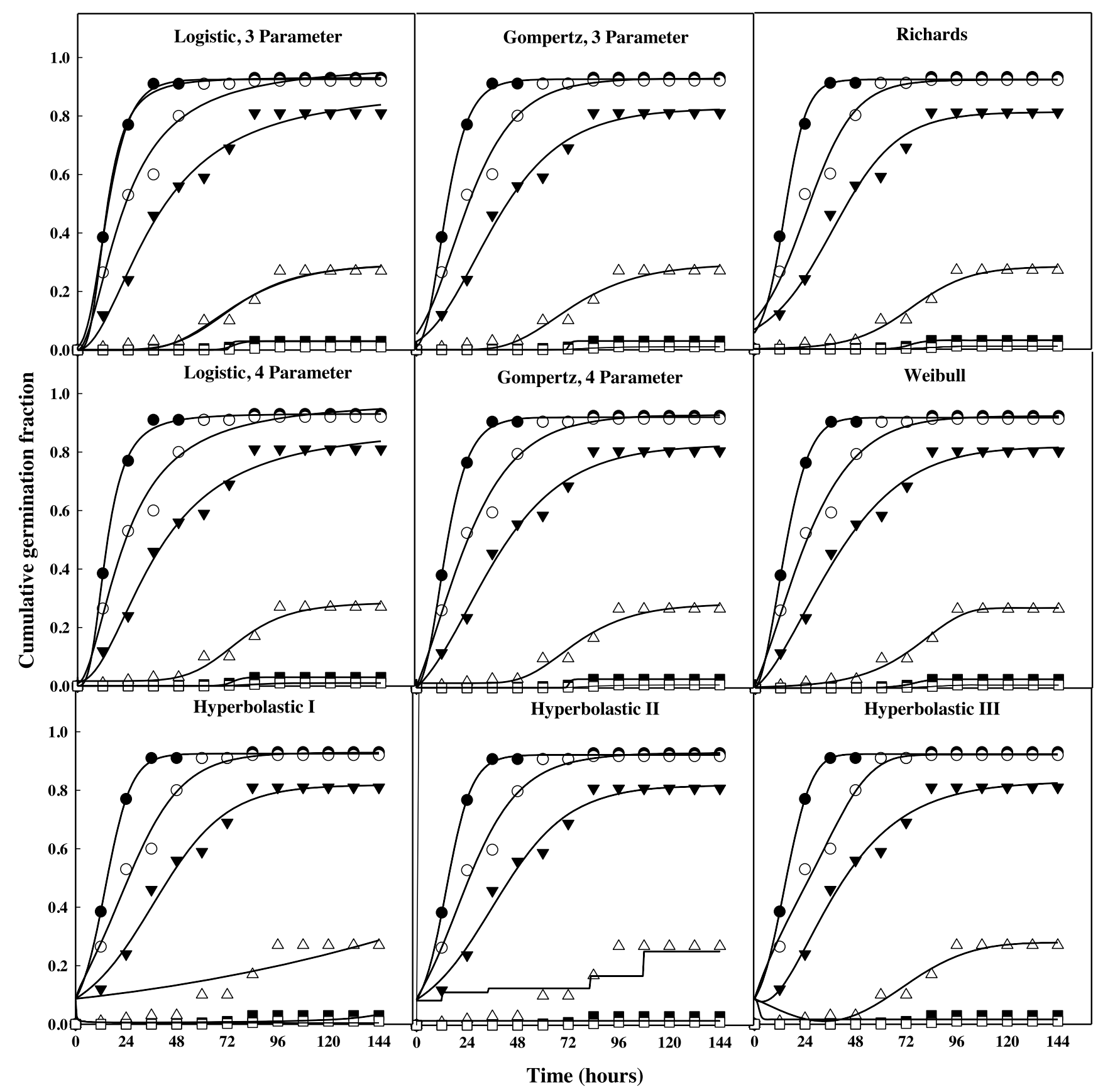

Fig. 2. Non-linear regression models for describe cumulative germination function cv. Nazok Shakhei under cadmium stress. Symbols ○: 0 ppm; $\bigcirc: 100 \mathrm{ppm}$; $\mathbf{\nabla}: 200 \mathrm{ppm} ; \Delta$ : $400 \mathrm{ppm}$; $\mathbf{\square}: 600 \mathrm{ppm}$ and $\square: 800 \mathrm{ppm}$.

Since cv. Yellow White did germinate or survive at the $800 \mathrm{ppm}$ cadmium concentration, it is considered the most sensitive cultivar to cadmium toxicity among the studied sesame cultivars. There was no seed germination at the $800 \mathrm{ppm}$ cadmium concentration for cv. Yellow White. The total seed germination fraction declined from 1 at no cadmium treatment to approximately 0.15 at the $600 \mathrm{ppm}$ cadmium concentration (Fig. 4).

Application of mathematical and empirical models allowed us to describe the seed germination patterns of sesame cultivars without the common limitations of single-value germination indices. For instance, in the studied sigmoid models, the outcome is either binary or dichotomous. The binary outcome in our study is either germinated (survived) or non-germinated seeds. The probability of seed germination as our outcome of interest is investigated under various levels of cadmium toxicity. Using natural logarithm $(\mathrm{ln})$, the odd ratio of seed germination (probability/1-probability) was used to model the probability of seed germination at various levels of cadmium toxicity. In sigmoid models, every unit increase in the $\mathrm{x}$ variable (cadmium concentrations) doesn't have the same decrease in the probability of seed germination. Thus, there isn't a consistent slope or changes in probability of seed germination versus increases of cadmium concentrations, 


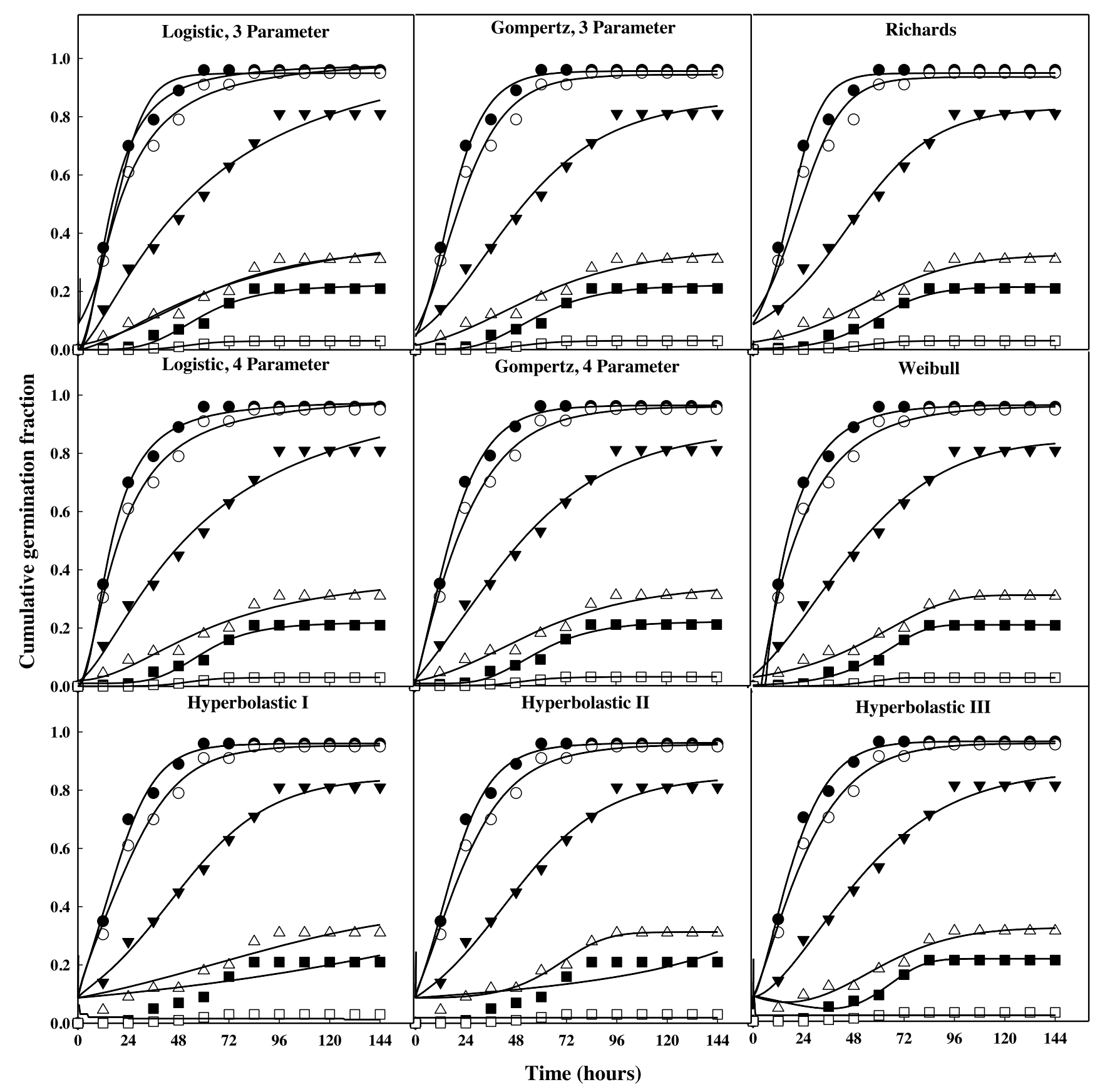

Fig. 3. Non-linear regression models for describe cumulative germination function cv. Oltan under cadmium stress. Symbols $\mathbf{0}$ : 0 ppm; O: $100 \mathrm{ppm} ; \boldsymbol{\nabla}: 200 \mathrm{ppm} ; \Delta: 400 \mathrm{ppm} ; \mathbf{\square}: 600 \mathrm{ppm}$ and $\square: 800 \mathrm{ppm}$.

instead the slope varies at different points across the cadmium concentrations. To interpret the relationship between seed germination and cadmium concentration, logic transformation is applied in our logistic regression analysis. This allows us to fit a line with a constant slope. In fact, this slope shows how the logodds of seed germination change with each increase in cadmium concentration. In other words, it tells us that for every $100 \mathrm{ppm}$ increase in cadmium concentration, the log-odds of seed germination decreased by the value of the estimated slope. The critical point of the sigmoid models as their important parameter, also shows us that the amount of cadmium concentrations inhibits completion of seed germination by half of its maximum potential. The maximum seed germination potential for each of the studied sesame cultivars under various levels of cadmium concentrations (carrying capacity) is also estimated as a parameter of Ymax in the applied mathematical models.

Fitted models provided a great result for describing the time course of seed germination. The predicted seed germination values, and our models' goodness of fit and residuals are presented in Table 2. The best model fit among studied empirical models was varied in each genotype under no stress conditions. The lowest AICc value - which is the best goodness of fit - was found for the Weibull model of the cv. Halil seed germination 


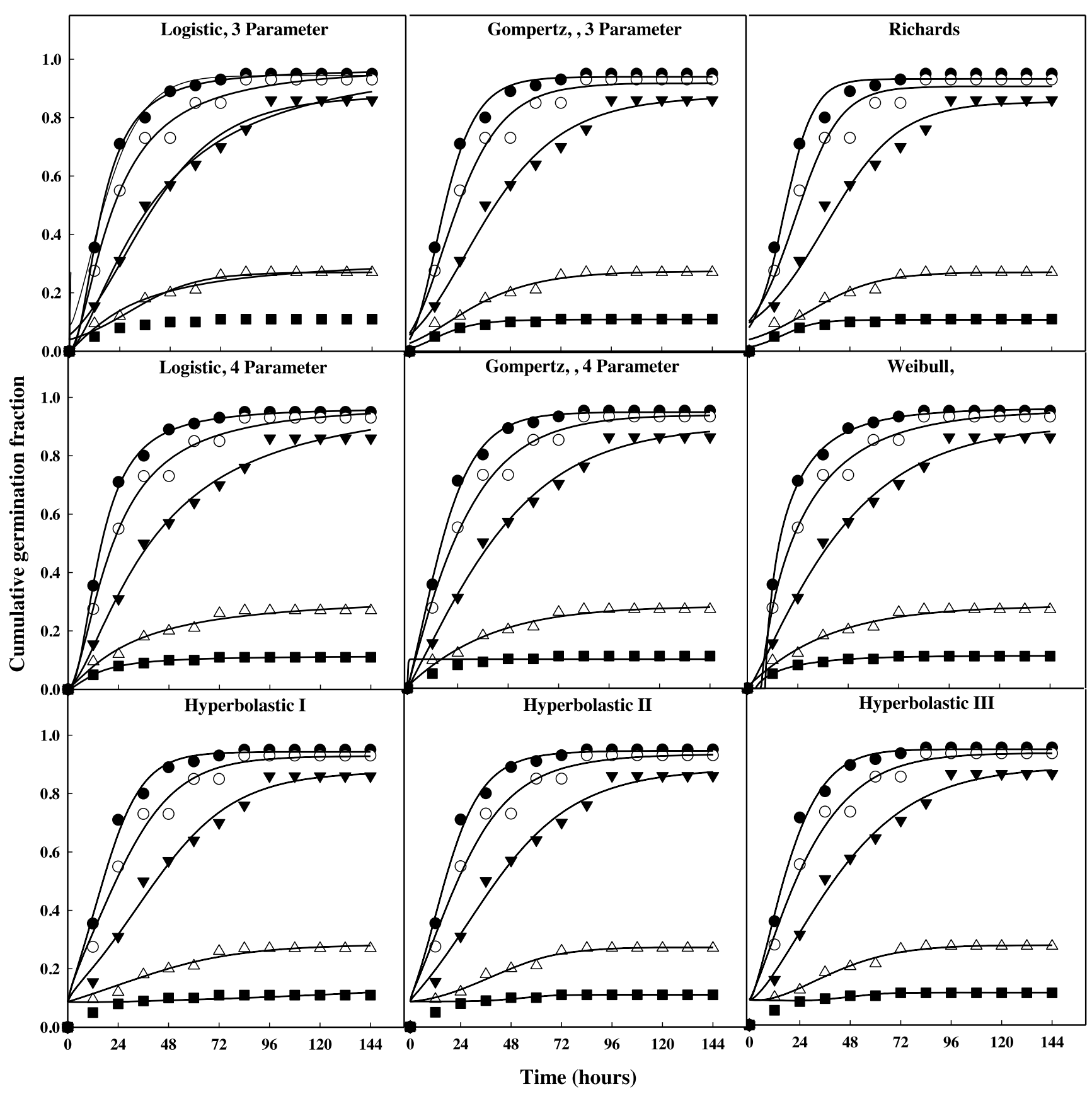

Fig. 4. Non-linear regression models for describe cumulative germination function cv. Yellow white under cadmium stress. Symbols $\mathbf{0} 0$ ppm; ○: $100 \mathrm{ppm} ; \boldsymbol{\nabla}: 200 \mathrm{ppm} ; \Delta: 400 \mathrm{ppm}$ and $\mathbf{\square}: 600 \mathrm{ppm}$.

$(\mathrm{AICc}=-35.3)$, However, in the case of Oltan $(\mathrm{AICc}=-22.4)$ and YellowWhite $(\mathrm{AICc}=-28.5)$, the three-parameter Logistic model performs better. The three-parameter Gompertz $(\mathrm{AICc}=$ -29.4) provide the best fit for Nazok Shakhei. Increase in cadmium concentrations, significantly influenced the best model fit for each individual genotype except for Yellow White. The three-parameter logistic model was always the best fitted model to describe germination of Yellow White (Tab. 2). At concentrations of $600 \mathrm{ppm}$ cadmium, the best data fit of seed germination for Oltan and Nazok Shakhei was obtained from the Weibull model with AICc of -27.5 and -51.2 respectively. Estimated parameters of all studied growth models are presented in Table 3. It is clear that hyperbolastic growth models are well suited to describe seed germination data; however, when data get close to the lower limits of germination fraction, the goodness of fit is drastically decreased for all studied cultivars. This was evident at cadmium concentrations above $400 \mathrm{ppm}$. Tabatabai et al. (2005) developed Hyperbolastic models to resolve this issue. These models have mobile inflection points, which provide them with special properties to fit the biological data. Of all the sigmoidal models tested, the Richardshas the least flexibility and in general has the poorest fit to the data. Our results suggest that hyperbolastic models perform well in modeling time-coarse seed germination, compared with competing 

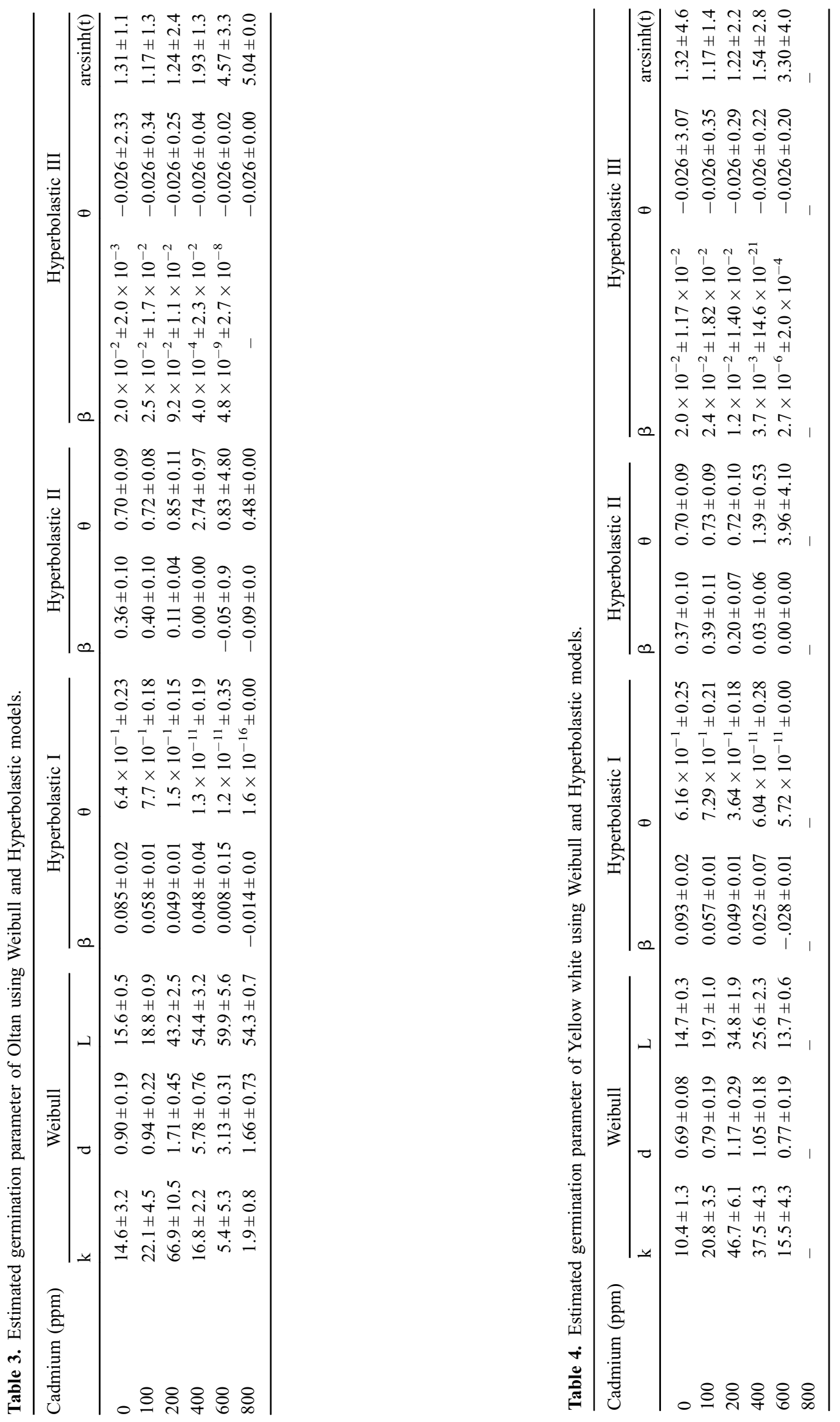

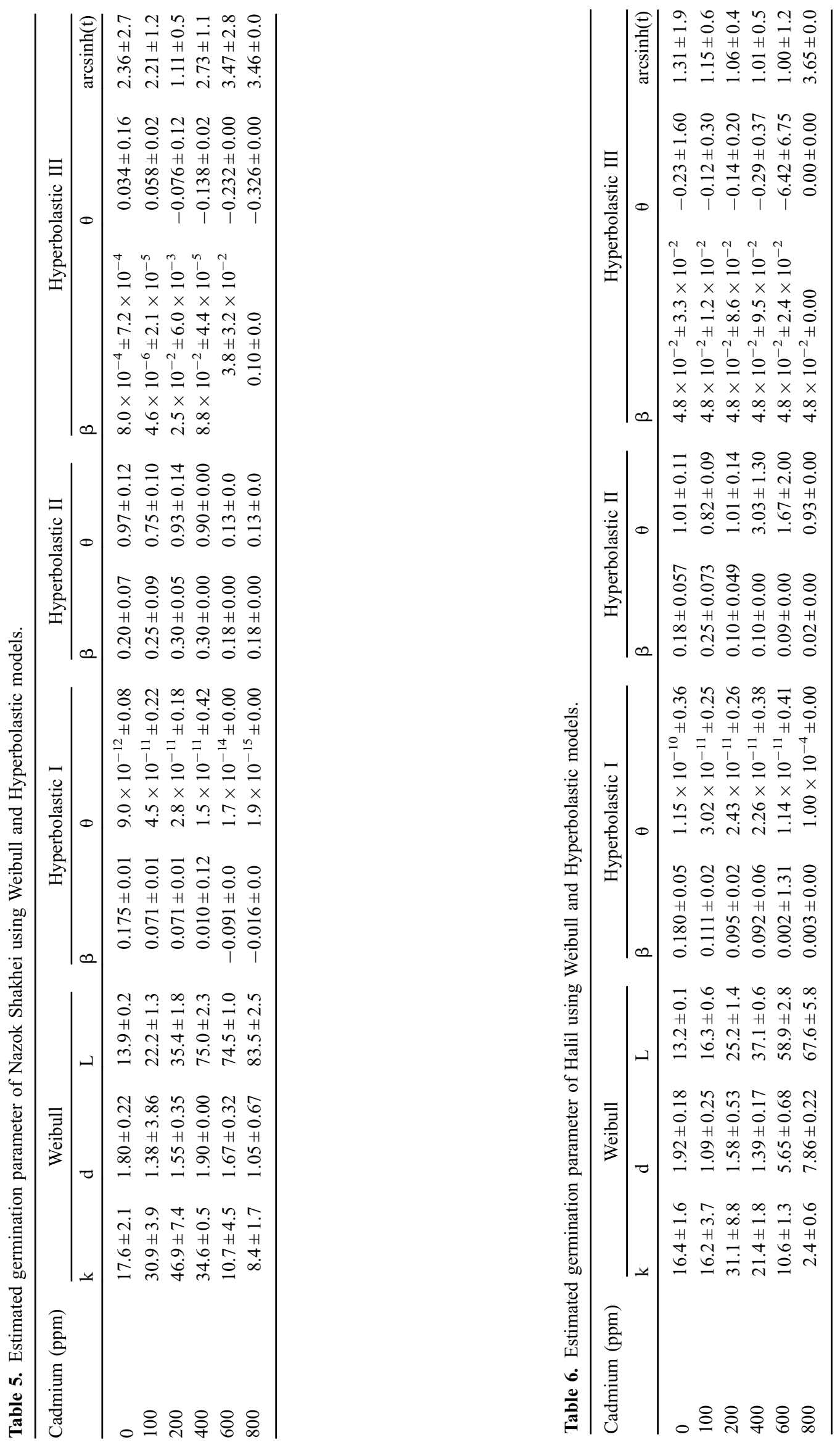


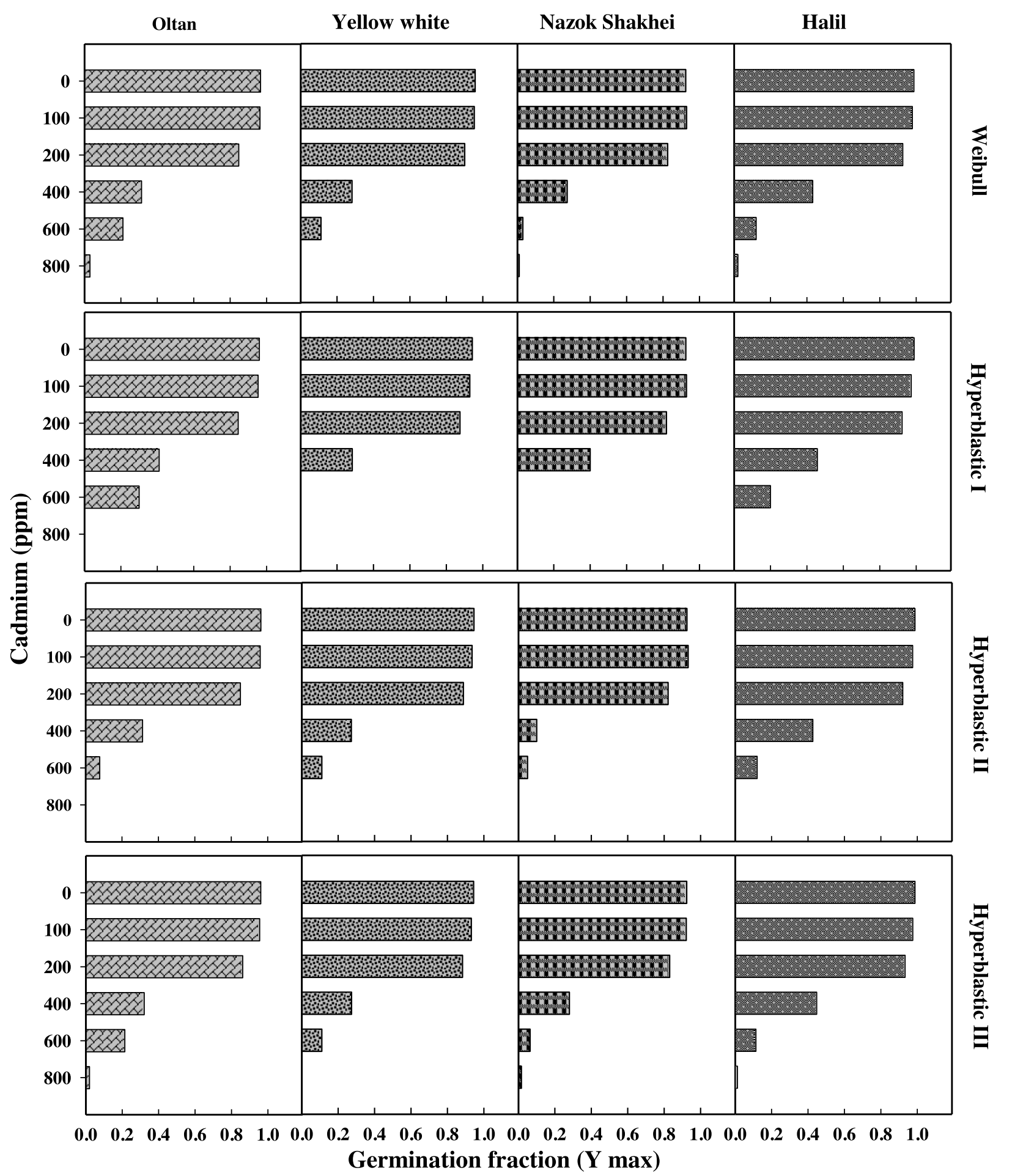

Fig. 5. Predicted germination fractions of sesame cultivars by Hyperplastics and Weibull function models under cadmium stress.

Gompertz, Richards, Weibull, and other commonly used models as shown in Table 2.

Our study results suggest that the shape flexibility of the investigated hyperbolastic models I to III leads to a good fit, and thus, these models could be considered when describing seed germination data. For our dataset, we observed that the Weibull function gave a reasonable representation of the data, followed closely by the hyperbolastic models type-I to type-III.
Estimated parameters for the rate of seed germination in the Weibull function $(\mathrm{k})$ declined as the concentration of cadmium exceeded $400 \mathrm{ppm}$ for all cultivars. In addition, due to an increase in cadmium toxicity, there was a higher lag time for germination to be completed (Tabs. 3-6). The reasons for the lower values for $\mathrm{R}^{2}$ and high values for AICc at the $800 \mathrm{ppm}$ cadmium concentrations, appear to be due to high toxicity and rapid morality rate in seeds that can be observed within the 
data. The estimated Ymax using hyperbolastic type III was very similar to the Weibull function. Results are in agreement with Tabatabai et al. (2011) regarding the similarity of hyperbolistic models to other growth models such as Logistic, Weibull and Gompertz. We suggest that the hyperbolastic growth model type-II (H2) is more flexible to fit the data than the other model types ( $\mathrm{H} 1$ and $\mathrm{H} 2)$, with the lowest AICc value in most of the cadmium concentrations (Tab. 2). As germination reduces when cadmium toxicity increases, the goodness of model fit also decreases. Our findings show that in many cases the best fitting model was not hyperbolastic growth models type-I (H1), type-II (H2), or type-III (H3), although they provided reasonable goodness of fit. It is also important to note that the Richards model provided less accuracy than all other models. The goodness of fit by hyperbolastic models can be attributed to their flexibility in shape. The cumulative seed germination time course of sesame genotypes was successfully fitted using nonlinear regression models including hyperbolastic growth models (Figs. 1-4). Therefore, we recommend that hyperbolastic growth models type-I (H1), type-II (H2), and type-III (H3), be considered among the available nonlinear models in seed biology. Results of model outputs predicting seed germination fraction using Weibull and hyperbolastic models are presented in (Fig. 5).

\section{Conclusion}

As germination reduces when cadmium toxicity increases, the goodness of model fit also decreases. Increasing cadmium concentration resulted in the germination fraction reduction from 1 to 0.4 at the $400 \mathrm{ppm}$. The recommended hyperbolastic growth model was type III or (H3) as it provided the best model with the lowest Corrected Akaike Information Criterion for $\mathrm{cv}$. Halil $(\mathrm{AICc}=-14.6)$ and cv. Nazok Shakhei, $(\mathrm{AICc}=-14.2)$.

Acknowledgments. Authors wish to thank Iranian Ministry of Science, Research and technology financial supports (Grant \#42/1/226405).

\section{References}

Afzal J, Hu C, Imtiaz M, et al. 2019. Cadmium tolerance in rice cultivars associated with antioxidant enzymes activities and $\mathrm{Fe} /$ Zn concentrations. Int J Environ Sci Technol 16(8): 4241-4252.

Ahmadi H, Golian A. 2008. Non-linear hyperbolastic growth models for describing growth curve in classical strain of broiler chicken. Res J Biol Sci 3(11): 1300-1304.

Akpofure R-R. 2012. Uptake of Heavy Metals By Okro (Hibiscus Esculentus) Grown on Abandoned Dump Sites in Effurun, Nigeria. J Emerg Trends Eng Appl Sci 3(4): 640-644.

Archontoulis SV, Miguez FE. 2015. Nonlinear regression models and applications in agricultural research. Agron J 107(2): 786-798. https://doi.org/10.2134/agronj2012.0506.

Asgher M, Khan MIR, Anjum NA, Khan NA. 2015. Minimising toxicity of cadmium in plants - Role of plant growth regulators. Protoplasma 252(2): 399-413.

Barrera A, Román-Román P, Torres-Ruiz F. 2018. A hyperbolastic type-I diffusion process: Parameter estimation by means of the firefly algorithm. BioSystems 163: 11-22. https://doi.org/10.1016/ j.biosystems.2017.11.001.
Benavides MP, Gallego SM, Tomaro ML. 2005. Cadmium toxicity in plants. Brazil J Plant Physiol 17(1): 21-34.

Bullied WJ, Bullock PR, Van Acker RC. 2012. Modelling soil water retention for weed seed germination sensitivity to water potential. Appl Environ Soil Sci. https://doi.org/10.1155/2012/812561.

Burnham KP, Anderson DR. 2002. Model selection and multimodel inference: a practical information-theoretic approach. Springer.

Chugh LK, Sawhney SK. 1996. Effect of cadmium on germination, amylases and rate of respiration of germinating pea seeds. Environ Pollution 92(1): 1-5. https://doi.org/https://doi.org/10.1016/ 0269-7491(95)00093-3.

DalCorso G, Farinati S, Maistri S, Furini A. 2008. How plants cope with cadmium: staking all on metabolism and gene expression. $J$ Integr Plant Biol 50(10): 1268-1280.

Das P, Samantaray S, Rout GR. 1997. Studies on cadmium toxicity in plants: A review. Environ Pollution 98(1): 29-36.

Deswal M, Laura JS. 2018. Effect of cadmium on respiration and enzyme activity in germinating pea (pisum sativum) seeds.

Dumur D, Pilbeam CJ, Craigon J. 1990. Use of the Weibull function to calculate cardinal temperatures in faba bean. J Exp Bot 41(11): 1423-1430.

Eby WM, Oyamakin SO, Chukwu AU. 2017. A new nonlinear model applied to the height-DBH relationship in Gmelina arborea. Forest Ecol Manag 397: 139-149. https://doi.org/10.1016/j. foreco.2017.04.015.

Fattahi B, Arzani K, Souri MK, Barzegar M. 2019. Effects of cadmium and lead on seed germination, morphological traits, and essential oil composition of sweet basil (Ocimum basilicum L.). Ind Crops Prod 138(February): 111584. https://doi.org/10.1016/j. indcrop.2019.111584.

Fenner M, Edwards P. 1991. Changes in germinability, ABA content and ABA embryonic sensitivity in developing seeds of Sorghum bicolor (L.) Moench induced by water stress during grain filling. New Phytologist 118: 339-347.

Gallego SM, Pena LB, Barcia RA, et al. 2012. Unravelling cadmium toxicity and tolerance in plants: insight into regulatory mechanisms. Environ Exp Bot 83: 33-46.

Gompertz B. 1825. On the nature of the function expressive of the law of human mortality, and on a new mode of determining the value of life contingencies. Philos Trans Royal Soc London 115: 513-583.

Hanc A, Tlustos P, Szakova J, Habart J. 2009. Changes in cadmium mobility during composting and after soil application. Waste Manag 29(8): 2282-2288.

ISTA. 2013. International rules for seed testing. International Seed Testing Association. Available from https://www.seedtest.org/.

ISTA. 2017. International rules for seed testing. International Seed Testing Association.

Munzuroğlu Ö, Zengin FK, Yahyagil Z. 2008. The abscisic acid levels of wheat (Triticum aestivum L. cv. Çakmak 79) seeds that were germinated under heavy metal $(\mathrm{Hg}++, \mathrm{Cd}++, \mathrm{Cu}++)$ stress. Gazi Univ J Sci 21(1): 1-7.

Richards FJ. 1959. A flexible growth function for empirical use. J Exp Bot 10(2): 290-301.

Seal CE, Barwell LJ, Flowers TJ, Merrett Wade E, Pritchard HW. 2018. Seed germination niche of the halophyte Suaeda maritima to combined salinity and temperature is characterised by a halothermal time model. Environ Exp Bot 155(April): 177-184. https://doi.org/10.1016/j.envexpbot.2018.06.035.

Shafii B, Price WJ, Swensen JB, Murray GA. 1991. Nonlinear estimation of growth curve models for germination data analysis.

Soler-Guilhen JH, Bernardes C de O, Marçal T de S, Oliveira WB dos S, Ferreira MF da S, Ferreira A. 2020. Euterpe edulis seed germination parameters and genotype selection. Acta Sci Agron 42. 
Tabatabai M, Williams DK, Bursac Z. 2005. Hyperbolastic growth models: Theory and application. Theor Biol Med Model 2: 1-13. https://doi.org/10.1186/1742-4682-2-14.

Tabatabai MA, Eby WM, Singh KP. 2011. Hyperbolastic modeling of wound healing. Math Comp Model 53(5-6): 755-768. https://doi. org/10.1016/j.mcm.2010.10.013.

Tanveer A, Javaid MM, Abbas RN, et al. 2017. Germination ecology of catchfly (Silene conoidea) seeds of different colors. Planta Daninha 35.

Tjørve KMC, Tjørve E. 2017. The use of Gompertz models in growth analyses, and new Gompertz-model approach: An addition to the
Unified-Richards family. PLoS ONE 12(6): 1-17. https://doi.org/ 10.1371/journal.pone.0178691.

Verhulst P-F. 1838. Notice sur la loi que la population suit dans son accroissement. Correspondance mathématique et physique publiée par a. Quetelet 10: 113-121.

Weibull W. 1951. A statistical distribution function of wide applicability. J Appl Mech 18(3): 293-297.

Zhang S, Zhang H, Qin R, Jiang W, Liu D. 2009. Cadmium induction of lipid peroxidation and effects on root tip cells and antioxidant enzyme activities in Vicia faba L. Ecotoxicology 18 (7): 814-823.

Cite this article as: Parmoon G, Moosavi SA, Poshtdar A, Siadat SA. 2020. Effects of cadmium toxicity on sesame seed germination explained by various nonlinear growth models. OCL 27: 57. 